\title{
Evaluation of volatile aroma compounds from Chinese wild grape berries by headspace-SPME with GC-MS
}

\author{
Faiz Ur RAHMAN ${ }^{1}$, Muhammad Azher NAWAZ², Ruitao LIU ${ }^{1}$, Lei SUN ${ }^{1}$, Jianfu JIANG ${ }^{1}$, Xiucai FAN ${ }^{1}$, \\ Chonghuai $\mathrm{LIU}^{1}$, Ying $\mathrm{ZHANG}^{1 *}$
}

\begin{abstract}
Evaluation of volatile aroma compounds from Chinese wild grape species aimed to explore new grape species via fruit aroma. In this study, the volatile organic compounds (VOCs) from ten grape cultivars belonging to nine different grape species were detected, by using headspace solid-phase microextraction with GC-MS. Chinese wild grape species were studied along with table grape (Muscat Hamburg, Concord) and wine grape (Cabernet Sauvignon) cultivars belonging to different origins. Total forty-five volatile compounds were detected, upon which several VOCs including pentanoic acid, cyclobutyl ester, maltol, (+)-neoisomenthol, and 8-methyloctahydrocoumarin were detected in Chinese wild grapes that have not been detected in other Vitis species. The results revealed that $\mathrm{C}_{6}$ volatile compounds were pre-dominant VOCs. Esters were found abundant in V. labrusca (Concord) and terpenoids were dominant in V. vinafera (Hamburg Muscat). The principal component analysis showed that Chinese wild grape cultivars $V$. yeshanensis, V. facifolia, V. davidii, V. betulifolia V. heyneana, V. amurensis and V. adenoclada are correlated with wine grape cultivar 'Cabernet Sauvignon', while table grape cultivars are distributed separately. These results can provide a reference for the utilization of new germplasm for specific purposes.
\end{abstract}

Keywords: Chinese wild grape species; SPME/GC-MS; volatile organic compounds (VOCs); principal component analysis.

Practical Application: The comparison of Chinese wild grape species with the European and American grape species on the base of volatile aroma compounds in grape berries provided a useful tool for breeding purpose and crop improvement.

\section{Introduction}

Grapes (Vitis vinifera L.) are consumed all over the world either directly (table grape) or processed (wine) (Chung et al., 1993; Wu et al., 2016). A large group of volatile organic compounds (VOCs) such as $\mathrm{C}_{6}$ compounds, carbonyls, esters, alcohols, and monoterpenes are found in grapes that impart specific aroma to grapes (Diéguez et al., 2003). The VOCs were more studied in wine grapes and rheological behavior in plant based beverages (Asproudi et al., 2016; Feng et al., 2017; Silva et al., 2020) compared with table grapes (Matsumoto \& Ikoma, 2016; RuizGarcía et al., 2014). The VOCs are one of the most important ingredients to determine the aroma quality of fruits; these VOCs have impact on the flavor of table grapes and also contribute towards the organoleptic character of wine.

Grapevine (genus Vitis) contains more than 70 species, in which more than 37 grapevine species originated in China (Wan et al., 2008). At present, cultivated grapes have four types, the American (V. labrusca L., especially the hybrids developed from V. vinifera L. and V. labrusca L.), the European (Vitis vinifera L.), the Amurensis (V.amurensis and its derivatives) and the Muscadine (V. rotundifolia Michx.). Among four types, only V. vinifera is used on large scale for wine production, which constitutes $71 \%$ of total production of grapes (Conde et al., 2007). In China, wines have also been made from Chinese wild Grapes species

and their hybrids such as wine produced in Northeast of China is mostly made from $V$. amurensis and its hybrids (Vitis amurensis $\times$ Vitis vinifera) and the quantity of wine production during 2002 was 5 million liters (Peng et al., 2005). Similarly, during 2003 in Guangxi province over 10,000 liters of wine was produced from another Chinese wild species ' $V$. heyneana' (Peng et al., 2005; Wan et al., 2008). Despites of wine making, Chinese wild species are also resistant to many pathogens such as resistance to crown gall (Agrobacterium tumefaciens), high resistance to powdery mildew (Uncinula necator), and extremely high resistance to ripe rot (Glomerella cingulata), and anthracnose (Elsinoë ampelina) (Gao et al., 2016; Mahanil et al., 2012; Ramming et al., 2011). Chinese wild grape species can be crossed easily with $V$. labrusca and $V$. vinifera. For genetic improvement of crops, wild species and their relatives have been widely used for breeding programs. Moreover, Chinese wild grape species do not have" foxy" flavored compound in berries that are not desirable but these compounds are common in American species (Alleweldt \& Possingham, 1988). Considering this, breeders are focusing to the Chinese wild grapes species but still their VOCs have not been studied properly. Thus it is important to study the VOCs in Chinese wild grape species that would be useful for breeding program to improve fruit quality of grapes. 
The present study was performed to evaluate grape VOCs and their composition from different species of Chinese wild grapes by using headspace-SPME combined with GC-MS. This study provides sufficient experimental evidence for further development and utilization of the Chinese wild grapes in crop improvement programs.

\section{Materials and methods}

\subsection{Plant material}

Based on the genetic background ten grape cultivars representing nine species were selected for this study (Figure 1, Table 1). All samples were collected from the experimental vineyard (grapes germplasm repository) at Zhengzhou Fruit Research Institute, Zhengzhou, China. The plants of the all grapevine species were planted in 2000 and are growing under judicial crop management practices such as including training, pruning, support form, irrigation, soil and fertility. For each cultivar, grape samples were collected from three vines; where three clusters were randomly selected from each vine, and total of nine clusters were taken for one cultivar and maturity of berries were identified from the seeds colour changed to dark brown with flesh tissue senescence. These samples were collected from August to September, 2019. For one replication, 30 to 120 berries $(100 \mathrm{~g}$ ) were collected from each vine at different positions, similarly, berries were collected from other two vines for remaining two replications and the numbers of berries depend upon the weight and size of individual berry. Samples were immediately frozen after harvest and temporarily stored at $-80^{\circ} \mathrm{C}$ until analysis. The grape berries were defrosted at $5^{\circ} \mathrm{C}$ before extracting the volatile compounds.

\subsection{Analysis of GC-MS}

In the experiment, headspace solid-phase micro-extraction (HP-SPME) was used for the concentration and isolation of volatiles. In a $15-\mathrm{mL}$ crimp cap phial, $\mathrm{NaCl}$ with concentration of $3 \mathrm{~g}$ and frozen tissue powder of $8 \mathrm{~g}$, were put together. When the solid-phase micro-extraction fiber was introduced to the headspace of the sample to adsorb the volatile analytes, the phial was exposed to water bath for $30 \mathrm{~min}$ at $45^{\circ} \mathrm{C}$. After extraction, the gas chromatography (GC) injector port exposed to the fiber for desorption.

The gas chromatography was prolonged for $2 \mathrm{~h}$ and 30 minutes at $250^{\circ} \mathrm{C}$, as we were using a SPME fiber (Supelco Inc., Bellefonte, Pennsylvania, USA; 50/30 $\mu \mathrm{m}$ DVB/CAR on PDMS) for the first time. The microextraction fiber was desorbed at $250{ }^{\circ} \mathrm{C}$ for 3 minutes, while headspace sampling. To identify relative contents and composition of volatile compounds, a 7890-5975C gas chromatograph-mass spectrometer (GC-MS; Agilent, Santa Clara, California, USA) was used. Gas chromatography (GC) was carried out under the following conditions: carrier gas, helium (99.99\%); chromatographic column, DB-225MS (30 m $\times 0.25 \mathrm{~mm} \times 0.25 \mathrm{um}$ ); chromatographic column, constant flow mode and flow rate $1 \mathrm{~mL}$ minutes ${ }^{-1}$; injection at $250{ }^{\circ} \mathrm{C}$, splitless; oven initial temperature was kept at $40^{\circ} \mathrm{C}$ for 3 minutes, then increased by $3{ }^{\circ} \mathrm{C}$ minutes ${ }^{-1}$ to $160{ }^{\circ} \mathrm{C}$ and retained for 2 minutes, and finally increased by $8{ }^{\circ} \mathrm{C}$ minutes ${ }^{-1}$ to $220^{\circ} \mathrm{C}$ and maintained for 3 minutes. Mass spectrometry (MS) was carried out under the following conditions: ion source at $230^{\circ} \mathrm{C}$; connector temperature, $280^{\circ} \mathrm{C}$; electron energy, $70 \mathrm{eV}$; electron ionization (EI); quadrupole at $150{ }^{\circ} \mathrm{C}$; scanning mass range, $50-550 \mathrm{~m} / \mathrm{z}$. National Institute of Standards and Technology (NIST) and Wiley libraries, were used to match the mass spectra of unknown compounds and according to their best match, compounds were allotted names. Compounds were confirmed
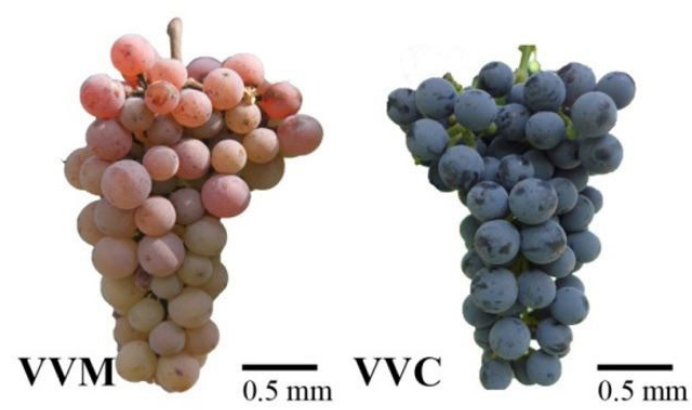

VLC
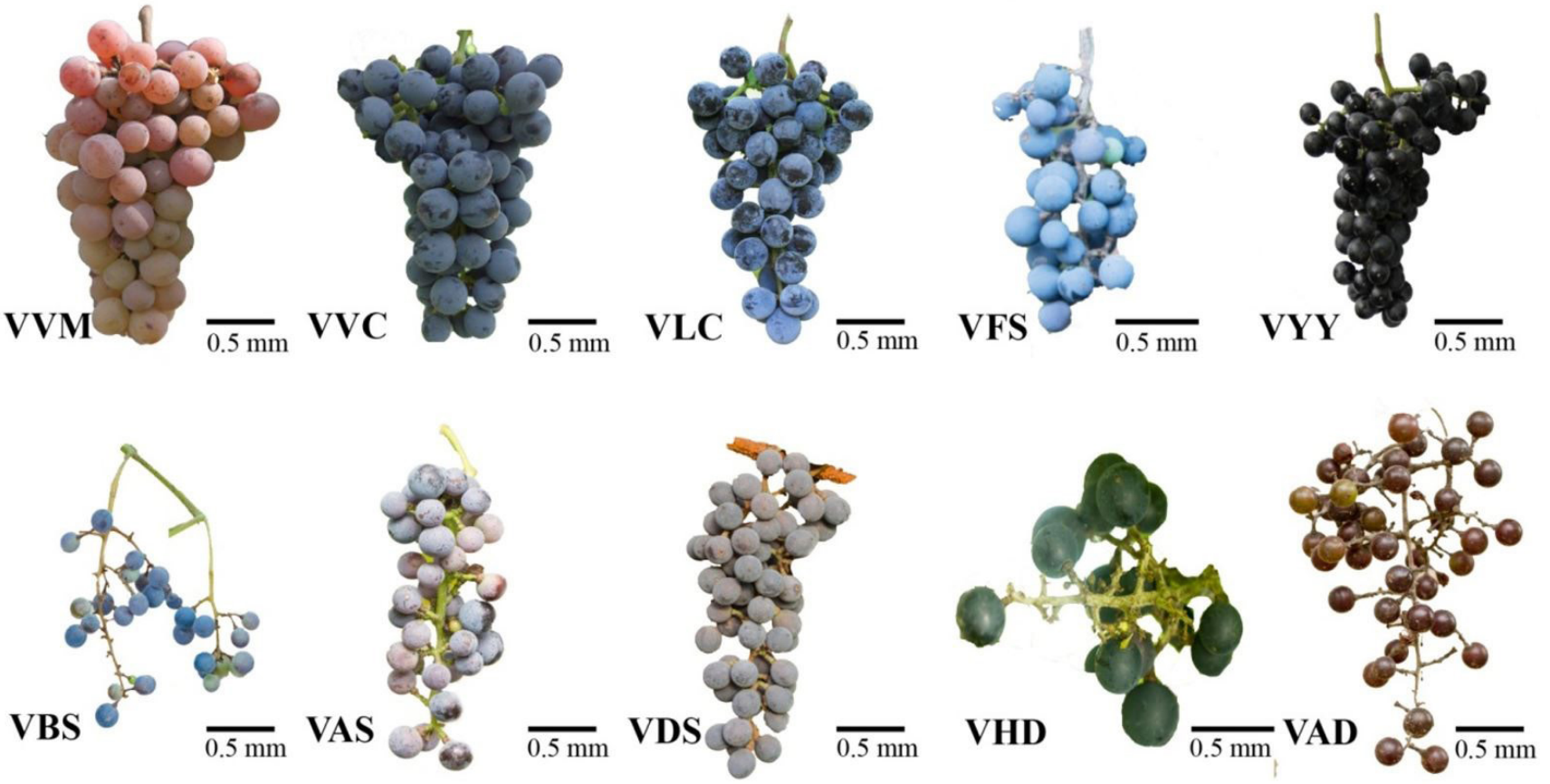

Figure 1. The grape berries from ten grape cultivars belonging to nine grape species used in this work. 
Table 1. Information related to grapes species and cultivars: origins, category, berry colour, berry shape, berry size, and berry weight.

\begin{tabular}{ccccccccc}
\hline Sr. No. & Abbr $^{\mathrm{a}}$ & Specie & Cultivars & Origins & Category & Berry Colour & ${\text { Berry size }\left(\mathrm{cm}^{2}\right)}_{\text {Berry weight }(\mathrm{g})}$ \\
\hline 1 & VVM & V. vinifera $^{\mathrm{b}}$ & Muscat hamburg & Eurasian & Table gape & Reddish-purple & $4.8 \pm 0.92$ & $5.2 \pm 0.51$ \\
2 & VLC & V. labrusca & Concord & $\begin{array}{c}\text { North } \\
\text { American }\end{array}$ & Table grape & Dark blue-purple & $3.5 \pm 0.73$ & $3.1 \pm 0.42$ \\
3 & VVC & V. vinifera & Cabernet sauvignon & Eurasian & Wine grape & Black & $1.7 \pm 0.54$ & $1.3 \pm 0.50$ \\
4 & VAS & V. amurensis & Shan putao & China & Unknown & Black & $1.6 \pm 0.49$ & $1.2 \pm 0.27$ \\
5 & VFS & V. facifolia & Sangye 943 & China & Unknown & Black & $1.2 \pm 0.44$ & $1.0 \pm 0.24$ \\
6 & VYY & V. yeshanensis & Yanshan 0947 & China & Unknown & Black & $0.7 \pm 0.11$ & $0.3 \pm 0.09$ \\
7 & VBS & V. betulifolia & Songshan huaye & China & Unknown & Black & $0.9 \pm 0.17$ & $0.5 \pm 0.13$ \\
8 & VDC & V. davidii & Ciputao & China & Unknown & Reddish-purple & $4.1 \pm 0.83$ & $4.8 \pm 0.49$ \\
9 & VHD & V. heyneana & Duan maoputao & China & Unknown & Black & $1.4 \pm 0.39$ & $1.0 \pm 0.37$ \\
10 & VAD & V. adenoclada & Shuangxi xianzhi01 & China & Unknown & Black & $1.5 \pm 0.41$ & $1.0 \pm 0.26$ \\
\hline
\end{tabular}

are the abbreviations for the cultivars used in this study; 'only $V$. vinifera has two cultivars because these two cultivars have different aroma types from each other's, all other species have only one cultivar.

by adding pure standard samples such as 1-hexanol, hexanal, and 2-hexenal, by their GC retention time.

\subsection{Statistical analysis}

The analysis of variance was performed and treatment means were compared using XLSTAT 2014.03.05 software. Duncan's multiple range tests was used to compare the difference among the treatment means at $P<0.05$. The results are reported as mean \pm SD of three replicates. To find the relationship between different cultivars and volatile compounds VOCs, Principal Component Analysis (PCA) was performed using R software (Lê et al., 2008). The clustered heatmap was performed using $\log 2$ normalized data of peak areas of volatile aroma compounds by a web tool (Metsalu \& Vilo, 2015).

\section{Results and discussion}

\subsection{Variation of volatile proportions in grape species}

In this study, forty five volatile organic compounds (VOCs) were identified and analyzed in seven classes, including six $\mathrm{C}_{6}$ compounds, four alcohols and carbonyls, ten esters, fourteen terpenoids, four shikimic acid and derivatives, five furans and two miscellaneous compounds (Table 2).

$\mathrm{C}_{6}$ volatile compounds contained five $\mathrm{C}_{6}$ aldehydes [hexanal, 2-hexenal, 3-hexenal, 2-hexenal, (E)- and 2,4-hexadienal, $(\mathrm{E}, \mathrm{E})-\mathrm{)}]$ and one $\mathrm{C}_{6}$ alcohol [2-hexen-1-ol, (Z)-]. In this study, $\mathrm{C}_{6}$ compounds were found pre-dominant VOCs in almost all grape species, ranging from $43.22 \%$ ( $V$. amurensis) to $95.66 \%$ (V. davidii) of the total VOCs. $\mathrm{C}_{6}$ compounds are commonly found VOCs in many fruits and are the basic background of volatiles in grapes (Watkins \& Wijesundera, 2006; Wu et al., 2019). $C_{6}$ volatile compounds are known as 'green leaf volatiles' and partly add herbaceous odour in grape juice; these are produced by enzymatic oxidation (Conde et al., 2007; Ribéreau-Gayon et al., 1975; Watkins \& Wijesundera, 2006). Three aldehydes hexanal, 2-hexenal, (E)- and 2,4-hexadienal, (E,E)- were found in all grapevine species, with different proportions. Hexanal is produced by the linoleic and linolenic acids oxidation under the lipoxygenase enzyme catalysis (Noguerol-Pato et al., 2012) and also increased by using different probiotic bacteria and packaging materials, during the ripening period (Akarca, 2020). 2-hexenal, (E)- is produced by the isomerization of (Z)-3-hexenal (Crouzet, 1999). These results can be compared to other V. vinifera studies (Meng et al., 2013; Noguerol-Pato et al., 2012; Wu et al., 2019; Jiang \& Sun, 2019). Other subtype of $\mathrm{C}_{6}$ compound was alcohol [2-hexen-1-ol, (Z)-] and proportion of this alcohol was lower than aldehydes. The $\mathrm{C}_{6}$ alcohols are generally converted from their respective aldehydes by an enzyme alcohol dehydrogenase (Crouzet, 1999). The rate of conversion from aldehyde to alcohol is strongly related with the activities of these enzymes, which is dependent on variety or Vitis species. Higher alcohol and carbonyl compounds were found less than $\mathrm{C}_{6}$ alcohols and $\mathrm{C}_{6}$ aldehydes, respectively. In all grape species, higher alcohols were detected not more than $1 \%$ of the total VOCs.

In this study, ten ester compounds were detected and they were found most abundant in V. labrusca with $24.31 \%$ of the total VOCs. Esters are present because of the activity of $\beta$-oxidation enzymes and specificity in the fatty acid metabolism pathway (Dudareva et al., 2004). From all ester compounds hexanoic acid, ethyl ester was found dominant and had a concentration of $11.46 \%$ of the total VOCs followed by butanoic acid, ethyl ester $(8.64 \%)$ in V. labrusca. Hexanoic acid, ethyl ester is produced by the condensation of hexanoic acid and ethanol (Zheng et al., 2012). It had been found that butanoic acid, ethyl ester and hexanoic acid, ethyl ester were some of the most essential VOCs related to strawberry aroma (Komes et al., 2005). In other cultivars the proportion of ester compounds were not more than $1 \%$ of the total VOCs, except V. betulifolia, V. davidii, V. amurensis and adenoloda in which no esters were identified. In this study, total fourteen terponoid compounds were identified, most were terpene alcohols except $\beta$-myrcene and $\mathrm{D}$-limonene. The terpene alcohols are formed by acetyl-coenzyme A from glucose during ripening of grape berries (Hellín et al., 2010) and they impart floral note to grape berries (Ribéreau-Gayon et al., 1975). The variation of aroma among different cultivars is mainly contributed by terpenoids (Salinas et al., 2004). In this study, terpenoids were identified in all cultivars and their proportion extensively varied from $0.16 \%$ to $55.31 \%$ of the total VOCs. Terpenoids were identified abundantly in $V$. vinifera (Hamburg Muscat), out of fourteen terpenoids twelve were identified in 'Hamburg Muscat' in which linalool had major contribution $(25.50 \%)$ of the total VOCs. The presences of various monoterpenes are associated with the 


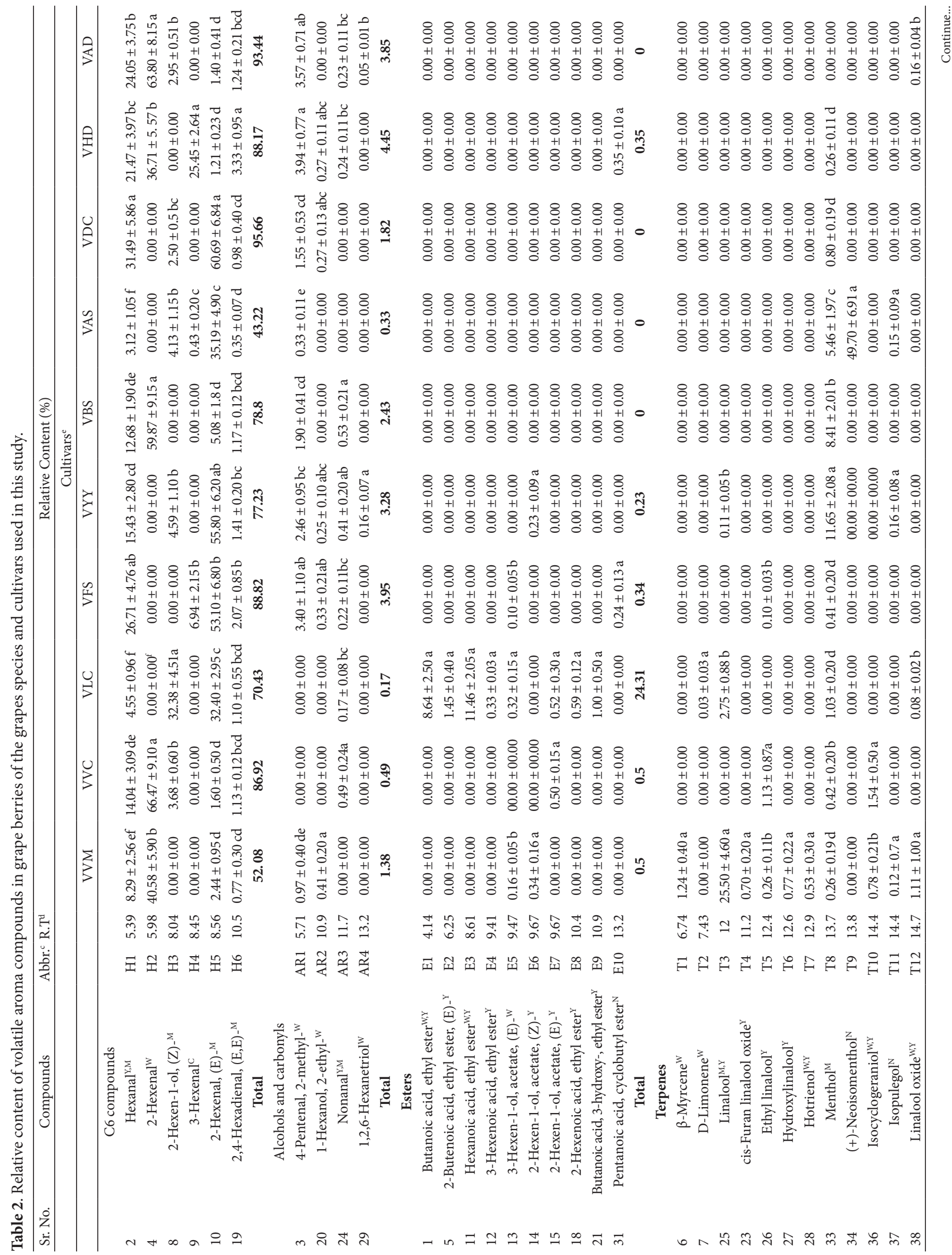




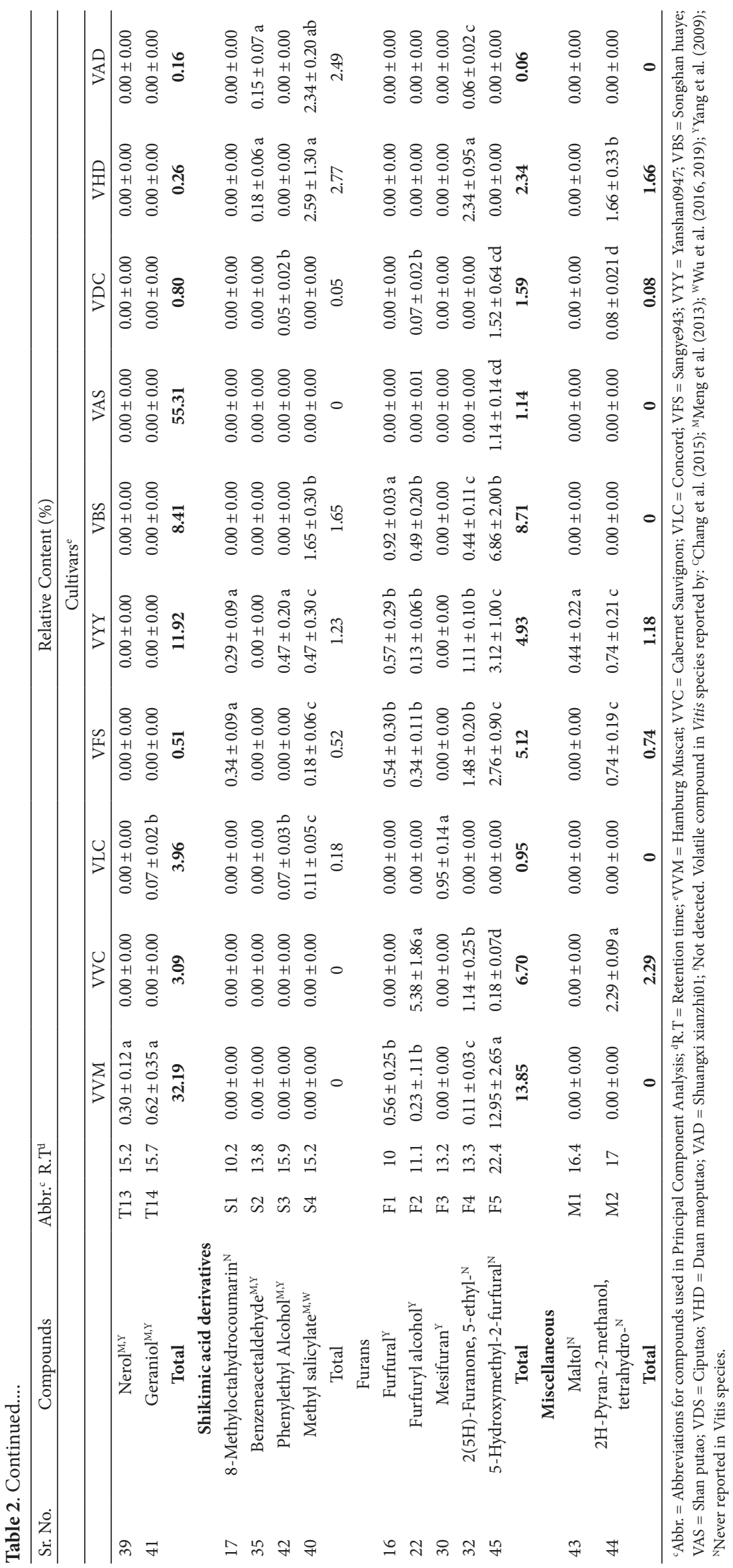


specific aroma and taste of Muscat grapes. (+)-neoisomenthol was identified in $V$. amurensis and its concentration was $49.70 \%$ of the total VOCs in $V$. amurensis, and this has not been reported for other Vitis species. (+)-neoisomenthol has menthol like cooling aroma (Chung et al., 1993). Terpenoids were also identified in other cultivars but lower in concentration.

In the study of shikimic acid derivatives, total four compounds were identified in which three were phenol volatiles (phenylethyl alcohol, methyl salicylate, and 8-methyloctahydrocoumarin) and one aromatic aldehyde (benzeneacetaldehyde). Shikimic acid derivatives were present in all species except $V$. amurensis and furans were found maximum in $V$. vinifera (Hamburg Muscat (13.85\%) compared with other cultivars. Mesifuran was only detected in $V$. labrusca which imparts strawberry flavour (Williams et al., 2005).

Furthermore, the hierarchical clustering (Figure 2) was conducted to find the inter-connectivity and closeness of cultivars and individual volatiles. The hierarchical clustering showed that V. vinifera (Cabernet Sauvignon) formed clusters with wild grape cultivars, other table grape cultivars 'Hamburg Muscat' and 'Concord' distributed separately and fall aside of the heatmap.

\subsection{Principal Component Analysis (PCA)}

Principal component analysis (PCA) was used to analyze the data of forty-five volatile organic compounds (VOCs) from different grapes species. Dim1 (first principal component) shows $44.90 \%$ variability and Dim2 (second principal component) shows $13.00 \%$ variability in the data (Figure 3 ). The V. vinifera (Hamburg Muscat) was distributed separately on Dim1: was characterized by terpenoids compounds (D-limonene, linalool, ethyl linalool, hydroxylinalool, linalool oxide, and nerol). The V. labrusca was distributed separately on Dim2 and was mainly characterized by ester compounds [butanoic acid, ethyl ester, 2-butenoic acid, ethyl ester, (E)-, butanoic acid, mesifuran, and phenylethyl alcohol]. Chinese grape cultivars ( $V$. facifolia, $V$. yeshanensis, V. betulifolia, V. davidii, V. heyneana, V. amurensis and $V$. adenoclada) highly correlated with $V$. vinifera (Cabernet Sauvignon) and were characterized by hexanal, 2-hexenal, (E)-, 2,4-hexadienal, (E,E)-, methyl salicylate, maltol, hotrienol, and furfural VOCs (Figure 3A). Dim1 highly correlates with butanoic acid, ethyl ester, 2-butanoic acid, ethyl ester, (E)-, $\beta$-myrcene, D-limonene, cis-furan linalool oxide, ethyl linalool, hydroxylinalool, nerol, geraniol and furfural while Dim2 highly

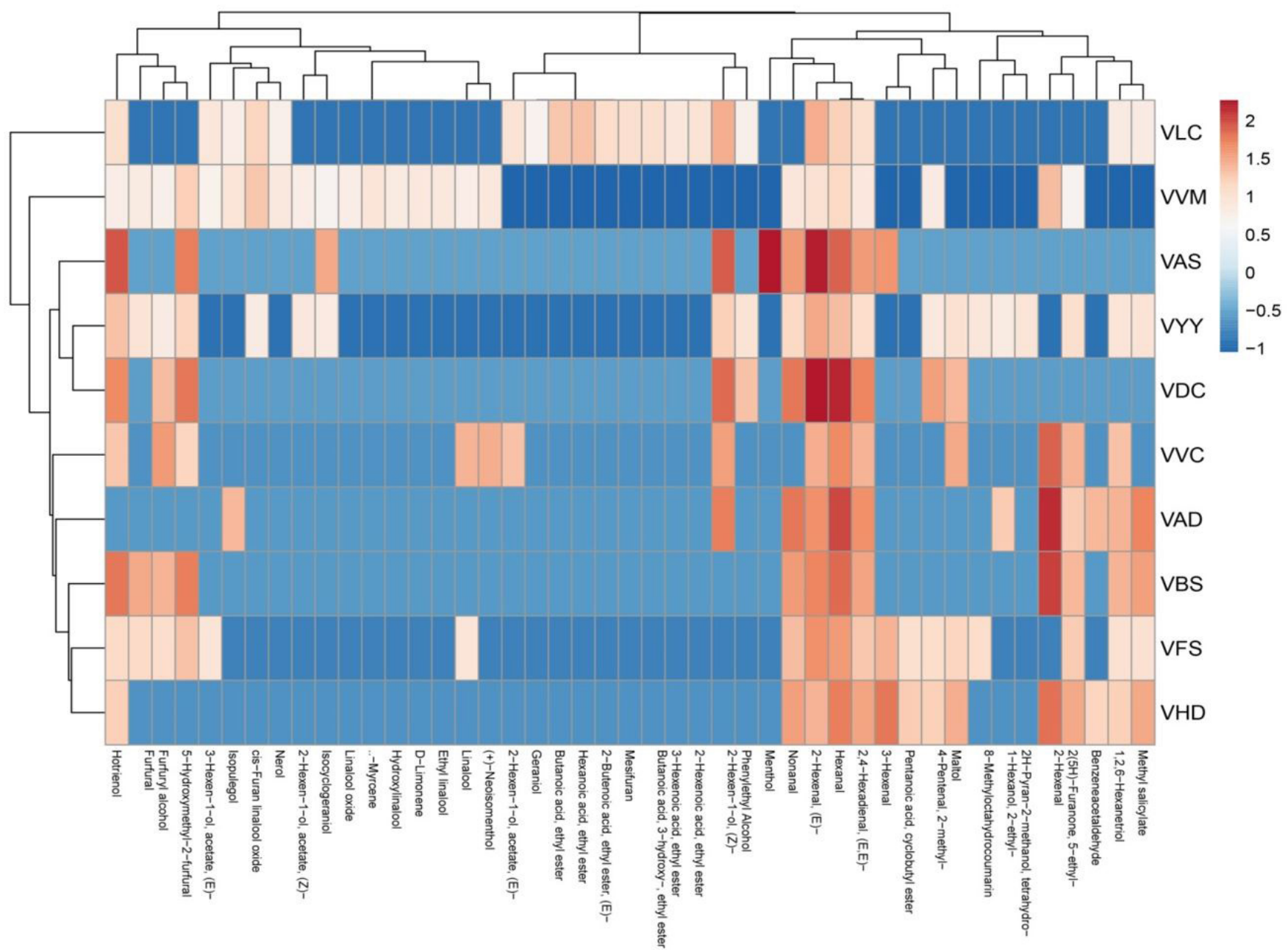

Figure 2. Heatmap visualization of volatile aroma compounds of 10 cultivars belonging to 9 different species VVM = Hamburg Muscat; VVC = Cabernet Sauvignon; VLC = Concord; VFS = Sangye943; VYY = Yanshan0947; VBS = Songshan huaye; VAS = Shan putao; VDS = Ciputao; $\mathrm{VHD}=$ Duan maoputao; $\mathrm{VAD}=$ Shuangxi xianzhi01. 
A
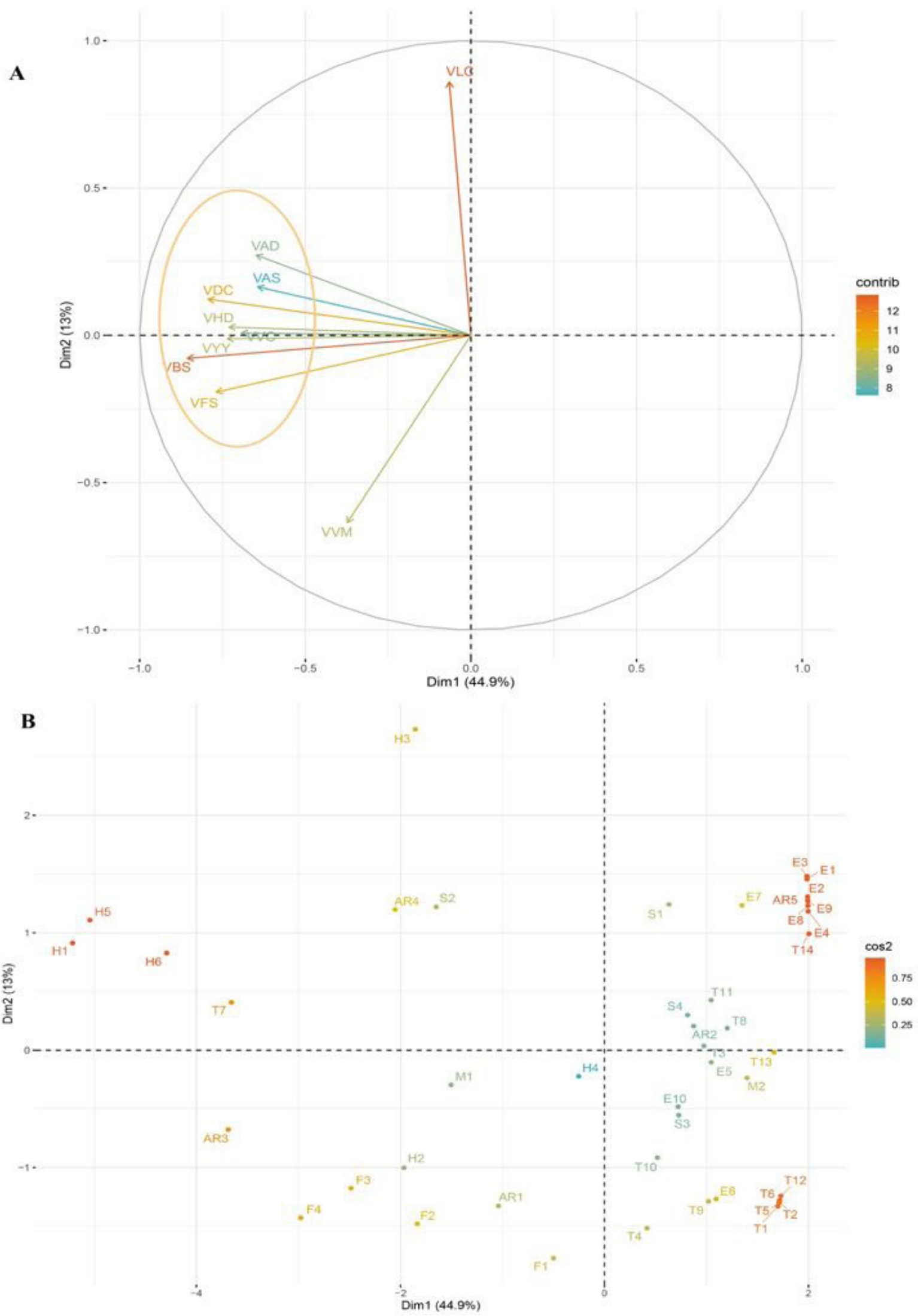

Figure 3. Overview of volatiles profiles of 10 grape cultivars belonging to nine different species. (A) Score plot analysis of all studied species, and (B) loading plot analysis of all contributors. (A) VVM = Hamburg Muscat; VVC = Cabernet Sauvignon; VLC = Concord; VFS = Sangye943; VYY = Yanshan0947; VBS = Songshan huaye; VAS = Shan putao; VDS = Ciputao; VHD = Duan maoputao; VAD = Shuangxi xianzhi01. Codes in (B) correspond to volatile compounds were listed in Table 2. 
correlates with hexanal, 2-hexenal, 2-hexen-1-ol, (Z)-, nonanal, 1,2,6-hexanetriol, hotrienol and benzeneacetaldehyde (Figure 3B). Overall, this PCA analysis revealed that Chinese wild grape cultivars were found similar with wine grape cultivar 'Cabernet Sauvignon', and the table grape cultivars V. vinifera (Hamburg Muscat) and V. labrusca distributed separately.

\section{Conclusion}

In this study, the proportion and composition of aromatic constituents of different grape species mainly varied with their genetic background. $\mathrm{C}_{6}$ volatile compounds were found dominant in V. heyneana, V.adenoclada, and V. davidii. Carbonyls and alcohols were relatively low in Vitis species. Esters were found abundant in V. labrusca and terpenoids were dominant in V. vinafera (Hamburg Muscat). Among the shikimic acid derivatives, and the furans, methyl salicylate and 5-hydroxymethyl-2-furfural were found abundant, respectively. Principal component analysis and hierarchical clustering showed that Chinese wild grape cultivars $V$. yeshanensis, V.facifolia, V. davidii, V. betulifolia, V. heyneana, V. amurensis, and $V$. adenoclada are correlated with wine grape cultivar 'Cabernet Sauvignon'. Table grape cultivars ' $V$. vinifera (Hamburg Muscat) and V. labrusca were distributed separately, mainly characterized by terpenoids and esters compounds, respectively. The result can provide a base for the utilization of new germplasm resources in wine making and grape processing industry. Additionally this information may be utilized for the selection of grape cultivars for different purposes, and grape crop improvement programs.

\section{Acknowledgements}

The authors wish to thank professional editors at Editage for their revision of the manuscript. This work was supported by National Key R\&D Program of China (2019YFD1001405), the China Agriculture Research System (CARS-29), the Agricultural Science and Technology Innovation Program (CAAS-ASTIP2017-ZFRI), and Henan Province Science Foundation [grant number 182300419915]. The funding bodies had no role in the study design, data collection, analysis and interpretation, decision to publish, or writing of the manuscript.

\section{References}

Akarca, G. (2020). Lipolysis and aroma occurrence in Erzincan Tulum cheese, which is produced by adding probiotic bacteria and ripened in various packages. Food Science and Technology, 40(1), 102-116. http://dx.doi.org/10.1590/fst.33818.

Alleweldt, G., \& Possingham, J. (1988). Progress in grapevine breeding. Theoretical and Applied Genetics, 75(5), 669-673. http://dx.doi. org/10.1007/BF00265585. PMid:24232343.

Asproudi, A., Petrozziello, M., Cavalletto, S., \& Guidoni, S. (2016). Grape aroma precursors in cv. Nebbiolo as affected by vine microclimate. Food Chemistry, 211, 947-956. http://dx.doi.org/10.1016/j. foodchem.2016.05.070. PMid:27283716.

Chang, E.-H., Jeong, S.-M., Hur, Y.-Y., Koh, S.-W., \& Choi, I.-M. (2015). Changes of volatile compounds in Vitis labrusca 'Doonuri'grapes during stages of fruit development and in wine. Horticulture, Environment and Biotechnology, 56(2), 137-144. http://dx.doi. org/10.1007/s13580-015-0068-3.
Chung, T. Y., Eiserich, J. P., \& Shibamoto, T. (1993). Volatile compounds isolated from edible Korean chamchwi (Aster scaber Thunb). Journal of Agricultural and Food Chemistry, 41(10), 1693-1697. http://dx.doi. org/10.1021/jf00034a033.

Conde, C., Silva, P., Fontes, N., Dias, A. C. P., Tavares, R. M., Sousa, M. J., Agasse, A., Delrot, S., \& Gerós, H. (2007). Biochemical changes throughout grape berry development and fruit and wine quality. Food, 1(1), 1-22.

Crouzet, J. (1999). Enzymes impliques dans la formation des aldéhydes et alcools en C6 (pp. 370-376). Paris: Lavoisier Tec\&Doc Oenologie. Fondements Sci. Tecnol.

Diéguez, S. C., Lois, L. C., Gómez, E. F., \& de la Peña, M. L. G. (2003). Aromatic composition of the Vitis vinifera grape Albariño. Lebensmittel-Wissenschaft + Technologie, 36(6), 585-590. http:// dx.doi.org/10.1016/S0023-6438(03)00064-1.

Dudareva, N., Pichersky, E., \& Gershenzon, J. (2004). Biochemistry of plant volatiles. Plant Physiology, 135(4), 1893-1902. http://dx.doi. org/10.1104/pp.104.049981 PMid:15326281.

Feng, H., Skinkis, P. A., \& Qian, M. C. (2017). Pinot noir wine volatile and anthocyanin composition under different levels of vine fruit zone leaf removal. Food Chemistry, 214, 736-744. http://dx.doi. org/10.1016/j.foodchem.2016.07.110. PMid:27507532.

Gao, Y.-R., Han, Y.-T., Zhao, F.-L., Li, Y.-J., Cheng, Y., Ding, Q., Wang, Y.-J., \& Wen, Y.-Q. (2016). Identification and utilization of a new Erysiphe necator isolate NAFU1 to quickly evaluate powdery mildew resistance in wild Chinese grapevine species using detached leaves. Plant Physiology and Biochemistry, 98, 12-24. http://dx.doi. org/10.1016/j.plaphy.2015.11.003. PMid:26590705.

Hellín, P., Manso, A., Flores, P., \& Fenoll, J. (2010). Evolution of aroma and phenolic compounds during ripening of 'superior seedless' grapes. Journal of Agricultural and Food Chemistry, 58(10), 63346340. http://dx.doi.org/10.1021/jf100448k. PMid:20438135.

Jiang, B., \& Sun, Z. Y. (2019). Phenolic compounds, total antioxidant capacity and volatile components of Cabernet Sauvignon red wines from five different wine-producing regions in China. Food Science and Technology, 39(3), 735-746. http://dx.doi.org/10.1590/fst.07818.

Komes, D., Ganiæ, K. K., Æosiæ, B., \& Lovriæ, T. (2005). Aroma profile of strawberry juice cocktail produced in industrial conditions. Kemija u Industriji, 54, 135-141.

Lê, S., Josse, J., \& Husson, F. (2008). FactoMineR: An R Package for Multivariate Analysis. Journal of Statistical Software, 25(1). http:// dx.doi.org/10.18637/jss.v025.i01.

Mahanil, S., Ramming, D., Cadle-Davidson, M., Owens, C., Garris, A., Myles, S., \& Cadle-Davidson, L. (2012). Development of marker sets useful in the early selection of Ren 4 powdery mildew resistance and seedlessness for table and raisin grape breeding. Theoretical and Applied Genetics, 124(1), 23-33. http://dx.doi.org/10.1007/s00122011-1684-7. PMid:21904846.

Matsumoto, H., \& Ikoma, Y. (2016). Effect of postharvest temperature on the muscat flavor and aroma volatile content in the berries of 'Shine Muscat' (Vitis labruscana Baily $\times$ V. vinifera L.). Postharvest Biology and Technology, 112, 256-265. http://dx.doi.org/10.1016/j. postharvbio.2015.09.004.

Meng, J. F., Xu, T. F., Song, C. Z., Li, X. L., Yue, T. X., Qin, M. Y., Fang, Y. L., Zhang, Z. W., \& Xi, Z. M. (2013). Characteristic free aromatic components of nine clones of spine grape (Vitis davidii Foex) from Zhongfang County (China). Food Research International, 54(2), 1795-1800. http://dx.doi.org/10.1016/j.foodres.2013.09.039.

Metsalu, T., \& Vilo, J. (2015). ClustVis: a web tool for visualizing clustering of multivariate data using Principal Component Analysis 
and heatmap. Nucleic Acids Research, 43(W1), W566-70. http:// dx.doi.org/10.1093/nar/gkv468 PMid:25969447.

Noguerol-Pato, R., González-Barreiro, C., Cancho-Grande, B., Santiago, J., Martínez, M., \& Simal-Gándara, J. (2012). Aroma potential of Brancellao grapes from different cluster positions. Food Chemistry, 132(1), 112-124. http://dx.doi.org/10.1016/j.foodchem.2011.10.042. PMid:26434270.

Peng, H., He, P., Huang, F., Zhu, J., Lin, M., Zhang, Y., \& Li, H. (2005). Comparative studies on the progenies with hermaphrodite flower of the interspecific hybrids of Vitis quinquangularis Rehd. South China Fruits, 24, 52-53.

Ramming, D. W., Gabler, F., Smilanick, J., Cadle-Davidson, M., Barba, P., Mahanil, S., \& Cadle-Davidson, L. (2011). A single dominant locus, Ren4, confers rapid non-race-specific resistance to grapevine powdery mildew. Phytopathology, 101(4), 502-508. http://dx.doi. org/10.1094/PHYTO-09-10-0237. PMid:21091183.

Ribéreau-Gayon, P., Boidron, J., \& Terrier, A. (1975). Aroma of Muscat grape varieties. Journal of Agricultural and Food Chemistry, 23(6), 1042-1047. http://dx.doi.org/10.1021/jf60202a050.

Ruiz-García, L., Hellín, P., Flores, P., \& Fenoll, J. (2014). Prediction of Muscat aroma in table grape by analysis of rose oxide. Food Chemistry, 154, 151-157. http://dx.doi.org/10.1016/j.foodchem.2014.01.005. PMid:24518327.

Salinas, M., Zalacain, A., Pardo, F., \& Alonso, G. L. (2004). Stir bar sorptive extraction applied to volatile constituents evolution during Vitis vinifera ripening. Journal of Agricultural and Food Chemistry, 52(15), 4821-4827. http://dx.doi.org/10.1021/jf040040c. PMid:15264921.

Silva, K., Machado, A., Cardoso, C., Silva, F., \& Freitas, F. (2020). Rheological behavior of plant-based beverages. Food Science and Technology, 40(Suppl 1), 258-263. http://dx.doi.org/10.1590/fst.09219.
Wan, Y., Schwaninger, H., Li, D., Simon, C., Wang, Y., \& He, P. (2008). The eco-geographic distribution of wild grape germplasm in China. Vitis-geilweilerhof, 47(2), 77.

Watkins, P., \& Wijesundera, C. (2006). Application of $z \mathrm{zNose}^{\mathrm{na}}$ for the analysis of selected grape aroma compounds. Talanta, 70(3), 595-601. http://dx.doi.org/10.1016/j.talanta.2006.01.032. PMid:18970814.

Williams, A., Ryan, D., Olarteguasca, A., Marriott, P., \& Pang, E. (2005). Analysis of strawberry volatiles using comprehensive two-dimensional gas chromatography with headspace solid-phase microextraction. Journal of Chromatography. B, Analytical Technologies in the Biomedical and Life Sciences, 817(1), 97-107. http://dx.doi. org/10.1016/j.jchromb.2004.05.021. PMid:15680793.

Wu, Y., Duan, S., Zhao, L., Gao, Z., Luo, M., Song, S., Xu, W., Zhang, C., Ma, C., \& Wang, S. (2016). Aroma characterization based on aromatic series analysis in table grapes. Scientific Reports, 6(1), 31116. http://dx.doi.org/10.1038/srep31116. PMid:27487935.

Wu, Y., Zhang, W., Yu, W., Zhao, L., Song, S., Xu, W., Zhang, C., Ma, C., Wang, L., \& Wang, S. (2019). Study on the volatile composition of table grapes of three aroma types. $L W T, 115,108450$. http://dx.doi. org/10.1016/j.lwt.2019.108450.

Yang, C., Wang, Y., Liang, Z., Fan, P., Wu, B., Yang, L., Wang, Y., \& Li, S. (2009). Volatiles of grape berries evaluated at the germplasm level by headspace-SPME with GC-MS. Food Chemistry, 114(3), 1106-1114. http://dx.doi.org/10.1016/j.foodchem.2008.10.061.

Zheng, L.-Y., Sun, G.-M., Liu, Y.-G., Lv, L.-L., Yang, W.-X., Zhao, W.F., \& Wei, C.-B. (2012). Aroma volatile compounds from two fresh pineapple varieties in China. International Journal of Molecular Sciences, 13(6), 7383-7392. http://dx.doi.org/10.3390/ijms13067383. PMid:22837701. 